\title{
Os Planos Municipais de Educação do Estado do Rio de Janeiro: um mapeamento de metas, estratégias e desafios
}

Jorge Najjar ${ }^{a}$ Marcelo Mocarzel ${ }^{b}$

Karine Morgan ${ }^{c}$

\section{Resumo}

Este artigo decorre de uma pesquisa realizada com os Planos Municipais de Educação de 89 municípios do Estado do Rio de Janeiro. A partir da abordagem do ciclo de políticas e da análise de conteúdo dos textos legais, foram selecionadas as categorias analíticas Gênero, Educação em Tempo Integral e Qualidade, buscando-se entender como as mesmas eram retratadas nos planos e que filiações ideológicas as amparavam. Ao se analisar o contexto da produção de textos e seus desdobramentos, buscou-se uma perspectiva crítica acerca da função do planejamento de políticas educacionais.

Palavras-chave: Plano Municipal de Educação. Ciclo de Políticas. Rio de Janeiro.

\section{Introdução}

Em 09 de janeiro de 2001, o Congresso Nacional aprovou o Plano Nacional de Educação (PNE) - Lei no 10.172 (BRASIL, 2001), elencando ações necessárias para a melhoria da Educação brasileira pelos 10 anos seguintes. Dentre as diretrizes apresentadas na lei, havia referência ao regime de colaboração entre os entes federados, indicando que estados, Distrito Federal e municípios deveriam trabalhar em parceria com a União para o alcance das metas. Reforçava-se aí a necessidade de elaboração de Planos Municipais de Educação (PME), como parte do compromisso do pacto federativo. Em 2014, com a aprovação

\footnotetext{
a Universidade Federal Fluminense, Niterói, RJ, Brasil.

b Universidade Católica de Petrópolis, Petrópolis, RJ, Brasil.

c Faculdades Integradas Maria Thereza, Niterói, RJ, Brasil. 
do novo PNE - Lei ${ }^{\circ} 13.005$ (BRASIL, 2014), essa necessidade passou a ser ainda mais latente.

Santos (2018) faz uma relevante crítica dessa transição entre os planos, indicando que

Em junho de 2014, mesmo tendo sido objeto de debates e proposituras nos diversos segmentos da sociedade desde 2010, foi aprovado e sancionado, sem apresentar avaliação do desempenho do plano anterior ou diagnóstico que demonstre a qualidade da Educação brasileira para além dos dados quantitativos, o novo PNE para o decênio 2014-2024 (p. 199).

É importante destacar que muitos autores, dentre eles Dourado, Grossi Junior e Furtado (2016), indicam que a principal razão para a não efetivação do PNE de 2011 foram os vetos presidenciais, que o corromperam em seu nascedouro, inviabilizando seu financiamento.

Na medida em que havia um maior compromisso político da União em fazer com que as metas do PNE saíssem do papel, e um envolvimento efetivo da sociedade civil, via Conferências Nacionais de Educação (Conae) e Fórum Nacional de Educação (FNE), em sua elaboração, avaliação e monitoramento, diferentemente do que ocorrera no primeiro plano, houve um maior envolvimento com esse documento, gerando, inclusive, a demanda aos estados e municípios para elaborarem seus próprios planos, e o anterior foi simplesmente esquecido, sem nenhum tipo de prestação de contas.

Cabe frisar que esse protagonismo dos municípios como entes autônomos é recente, sobretudo, no que tange às questões educacionais. Pereira (2018) aponta que a formalização dos sistemas municipais de Educação, ocorrida em grande parte após a redemocratização, em 1988, possibilitou que os municípios normatizassem a gestão educacional de acordo com suas próprias demandas, consagrando o poder local como locus de processos decisórios relevantes para seus habitantes, com suas próprias redes de escolas municipais a serem geridas pelas secretarias municipais de Educação e suas próprias regras e procedimentos fiscalizadores, a serem aplicadas pelos conselhos municipais de Educação. Os planos municipais integram esse arcabouço ${ }^{1}$.

Optou-se por não referenciar cada um dos Planos Municipais pesquisados, para não comprometer a fluidez do texto. Todos os Planos podem ser consultados em http://www.mprj.mp.br/conheca-o-mprj/areas-deatuacao/educacao/controle-social-na-educacao/planos-municipais-de-educacao. 
Buscamos analisar o texto aprovado dos PME de 89 municípios do Estado do Rio de Janeiro ${ }^{2}$, interpretando seus diferentes enfoques e enquadramentos ideológicos, visando a compreender a articulação dos mesmos com as políticas educacionais estaduais e federais, em especial o PNE. O estado possui 92 municípios, mas três deles ainda não haviam aprovado seus planos quando concluímos a pesquisa: Volta Redonda, Niterói e Rio de Janeiro. Trata-se de algo significativo, por serem três dos dez municípios mais ricos do estado (incluindo a capital, o maior e mais rico).

Vale dizer, também, que os planos municipais aqui analisados foram os que inicialmente se efetivaram em lei, pois havia um processo, acompanhado pelo Ministério Público e por equipes de técnicos vinculados às Secretarias Estaduais de Educação e ao Ministério de Educação, para a modificação de partes dos planos consideradas equivocadas, omissas ou imprecisas. Desse processo, ainda em andamento quando da formulação do presente artigo, novos textos de plano estão surgindo. Optamos por continuar trabalhando com os textos originais, pois acreditamos serem eles um reflexo mais vivo das discussões e disputas ocorridas no âmbito municipal.

Como fio teórico-metodológico da pesquisa, escolhemos a abordagem do ciclo de políticas, formulada inicialmente por Ball e Bowe (1992). Assim como os autores, nós nos afastamos da perspectiva de que as políticas públicas são simplesmente implementadas pelo Estado; buscamos, por outro lado, um modelo complexo e multifacetado, ancorado em diferentes contextos. Sem abrir mão do lugar do Estado nas políticas educacionais, os autores questionam a visão "estadocêntrica", em que as políticas são totalizantes e não deixam espaço para a ação humana de contestação, despindo os sujeitos de poder decisório. Nesta pesquisa, entendemos que as políticas compõem um ciclo entre formulação, influências e prática, que não cessa e sempre agrega novos elementos interpretativos, bem como que os sujeitos têm papel protagonista na interpretação, tradução e atuação das políticas (BALL; MAGUIRE; BRAUN, 2016).

Souza e Martins (2014, p. 14) apontam que no ano de 2011, com o fim da vigência do último PNE, "contabilizou-se a existência de 2.181 municípios (39,2\% de 5.565) sem PME, enquanto, mais recentemente, em 2014, o montante é de 14 estados

\footnotetext{
2 A pesquisa que deu origem a este artigo foi realizada entre 2017 e 2018, pelo Núcleo de Estudos e Pesquisas em Gestão e Políticas Públicas em Educação da Universidade Federal Fluminense (Nugeppe/ UFF), coordenado pelo prof. Dr. Jorge Najjar. Além dos autores, outros integrantes fizeram parte desta pesquisa e a quem agradecemos pelas contribuições: Leonardo Dias da Fonseca, Pablo Bispo dos Santos, Lucy Teixeira, Alba Valéria Baensi, Alexandre Najjar, Gisele Coelho, Camila Bacelar de Araújo, Gabriella Félix Cupolillo, Silvana Malheiro, Laila Gonçalves, Lana Mara Fontes, Débora Quirino, Verônica Mattedi e Fábio Araújo de Souza.
} 
sem PEE (54\% do total de 26)". Muitos municípios ainda não se constituíram como sistemas, dependendo diretamente dos estados e da União. "O desafio para os municípios é elaborar um plano que guarde consonância com o PNE e, ao mesmo tempo, garanta sua identidade e autonomia" (BRASIL, 2005, p. 10). Após as análises, vemos que parte desse desafio ainda parece inalcançado.

A partir da promulgação da Lei n ${ }^{\circ} 13.005$ (BRASIL, 2014), que instituiu o atual PNE (2014-2024), os municípios e estados precisavam, ainda em 2015, apresentar seus novos planos. É fundamental considerar que o PME deve ser do município, e não apenas da rede ou do sistema municipal. O PME é de todos que moram no território; portanto, todas as necessidades educacionais do cidadão devem estar presentes no plano, o que vai além das possibilidades de oferta educacional direta da Prefeitura.

Por esse motivo, a intersetorialidade é uma premissa estratégica para dar sentido ao plano, considerando que o projeto de Educação de um município não é tarefa apenas do órgão gestor da rede de ensino, mas do conjunto de instituições dos governos, com a participação ativa da sociedade. O PME tem a responsabilidade de traduzir e conciliar os desejos, as necessidades e as capacidades educacionais do município para a oferta da Educação Básica (em todas as suas etapas e modalidades) e também de Ensino Superior. O documento precisa levar em consideração a trajetória histórica, as características socioculturais e ambientais, a vocação e a perspectiva de futuro do município.

Ao lado do PNE, os Planos Estaduais de Educação (PEEs), o Plano de Educação do Distrito Federal (PEDF) e os Planos Municipais de Educação (PMEs), pelo menos em tese, passam a ser tratados pela literatura pertinente como instrumentos estratégicos de gestão democrática da Educação, uma vez que, além de terem de prever a necessária participação sociopolítica, agora na implantação, no acompanhamento e na avaliação do plano, também devem implicar explicitação de princípios, de competências de políticas públicas relativas não apenas à esfera federal, mas às esferas estadual, do Distrito Federal e municipal, a ser atestada na diagnose dessas múltiplas realidades educacionais e, a um só tempo, na elaboração de diretrizes a ela coesas, consubstanciadas por meio da definição de metas, objetivos e prazos (SOUZA; MARTINS, 2014, p. 13).

A visão do plano de Educação como exercício da gestão democrática também é confirmada por Teixeira (2012, p. 36), quando afirma que esses podem ser 
aliados, ordenando os sistemas de ensino, de modo que se superem. Mas, da mesma maneira, a autora pondera que os planos podem ser obstáculos da gestão, se "forem encarados como mais uma atividade burocrática cuja elaboração está apenas ligada ao cumprimento da lei e em função da coerção que ela representa: ou ainda se forem encarados como mecanismos de manobra política $[\ldots] "$ ".

Entendendo que a Análise de Conteúdo é um conjunto de técnicas de análise de comunicações, que utiliza procedimentos sistemáticos e objetivos de descrição do conteúdo das mensagens, indicadores (quantitativos ou não) que permitem a inferência de conhecimentos relativos às condições de produção/recepção dessa mensagem (BARDIN, 1994), utilizamos suas técnicas com o intuito de relacionar a micropolítica à macropolítica, bem como projetar possíveis desdobramentos advindos da disputa ideológica contida nos textos dos planos. Assim, esta pesquisa nos levou a caminhos inéditos, em que a colaboração entre os entes perdeu espaço para projetos politicamente mais fortes.

O planejamento das políticas educacionais tem como um de seus objetivos colocar as ações em ordem, definindo, de tudo o que é pensado e proposto, o que deve ser tratado como prioridade, canalizando esforços e recursos para sua efetivação. Para Bordignon, "as políticas e as diretrizes dizem respeito à orientação e às finalidades da ação governamental e, obviamente, devem constituir os fundamentos do plano" (2014, p. 32). Logo, formular políticas já é, em si, uma forma de planejamento.

No campo da política educacional, o planejamento padece de vários problemas. $\mathrm{Se}$, por um lado, os tecnocratas colocam sobre o planejamento economicista da Educação a base para todas as suas resoluções, os educadores, por sua vez, acabam por abrir mão de qualquer planejamento efetivo, em muito, por carecerem de técnicas adequadas para planejarem-na em suas diversas dimensões. Mendes faz dura crítica a esse duplo caminho que o planejamento de políticas públicas educacionais trilhou no Brasil:

Já vimos que o plano elaborado pelos pedagogos se esquivou, por motivos de filosofia política, de fixar uma política de Educação. Agora, os economistas, por um passe de mágica, por razões que seriam, antes, de filosofia da cultura, ambicionando realizar a política da Educação segundo a ótica economicista, se afastam, sem o perceber, tanto da Educação, quanto da própria economia (2000, p. 21). 
Ainda de acordo com Mendes, as origens institucionais do planejamento em Educação, mais precisamente do ponto de vista das políticas educacionais, encontra-se na Lei de Diretrizes e Bases (LDB) de 1961. Se o texto legal falava em planos educacionais como atribuições do Conselho Federal de Educação, a prerrogativa do planejamento parece ter sido esquecida dos demais artigos, dando uma falsa noção de importância.

Nas palavras de Ferreira (apud BORDIGNON, 2014), planejar é o oposto de improvisar; é refletir antes, durante e depois da ação para que a mesma tenha o melhor desenvolvimento possível. Ter um plano não significa ter, necessariamente, um planejamento. É possível ter um plano de maneira improvisada, por mais que ele anteceda à ação. Planejar é refletir sobre diversas possibilidades, com a antecedência necessária e analisando todas as variáveis possíveis.

Dentre diferentes abordagens possíveis, optamos por eleger alguns temas considerados mais complexos ou "polêmicos", a fim de pesquisarmos o enquadramento dado por cada município em seu plano. Foram recortadas as seguintes temáticas para análise: Gênero, Educação Integral em Tempo Integral e Qualidade. É preciso destacar que, na pesquisa que deu origem a este artigo, outros conceitos também foram analisados, como Formação e Valorização, Financiamento e Gestão, mas escolhemos os três anteriores por conterem mais elementos ricos em contradições.

\section{Gênero}

Essa categoria traz uma discussão muito cara à sociedade contemporânea. $\mathrm{O}$ debate teórico sobre gênero vem ganhando destaque na academia e nos meios políticos. Seu nascedouro está em 1949, com a publicação da obra clássica de Simone de Beauvoir, "O Segundo Sexo", que defende a desnaturalização da condição social da mulher na sociedade, denunciando o machismo, que até hoje é reforçado em muitos contextos. Começa-se a buscar uma separação conceitual entre sexo (referente à biologia) e de gênero (referente à identidade sexual, à orientação sexual e à condição social dessa identidade). Nas políticas educacionais, a ótica de gênero também ganha força na última década, sobretudo nos debates curriculares, e passa a disputar espaço e representatividade, contrapondo-se às escassas e tímidas e, às vezes, conservadoras iniciativas de Educação sexual (BAYARDO, 1995).

Apesar do debate sobre gênero na Educação ter, nos últimos anos, ganhado força e mobilizado verdadeiros confrontos, sobretudo no que tange às disputas entre movimentos Lésbicas, Gays, Bissexuais, Transsexuais (ou Transgêneros) 
e Queer (LGBTQ+) ${ }^{3}$ e movimentos religiosos conservadores, quando se trata dos textos dos PME, há quase um silêncio acerca da temática. Mas, como nos lembra Bardin (1994), o silêncio também nos diz coisas. Na medida em que muitos municípios não tratam desse assunto, que se relaciona diretamente com o combate à discriminação e à violência e com o fomento à tolerância e à diversidade sexual, essa omissão põe em destaque a polêmica que ronda essa pauta, principalmente em uma época de reafirmação do pensamento conservador.

Porém, alguns temas relacionados às questões de gênero foram alvo de análise por determinados planos. Estratégias relacionadas à violência doméstica e sexual, sobretudo contra a mulher, aparecem em 34 (cerca de 38\%) dos PME analisados, ressaltando a importância do ambiente escolar para a proteção e combate a essas práticas. Entretanto, somente 21 planos abordam diretamente as questões de gênero em seu corpo, o que equivale a menos de $1 / 4$ dos textos legais analisados.

Entre os que abordam a temática, Angra dos Reis, por exemplo, aponta em plano a necessidade de garantir acesso, permanência e conclusão dos estudos de crianças, jovens, adultos, idosos, a fim de subsidiar políticas públicas de promoção da igualdade étnico-racial, de gênero, sexual e religiosa na sociedade e combate às desigualdades.

O município de Aperibé, por sua vez, trata das questões de gênero em três metas, sem que haja uma direcionada a isso. Em suas estratégias, recomenda o acesso a atividades artísticas, esportivas e culturais e a políticas de formação continuada que envolvam as famílias, os estudantes e os profissionais da Educação, para que discussões sobre direitos humanos, gênero e sexualidade sejam alargadas e que se busque, coletivamente, formas de superar as discriminações e os preconceitos.

Porém, é o município de Cabo Frio o que mais se aprofunda na questão, ao indicar a necessidade de garantir uma Educação inclusiva, não-sexista, não racista e sem discriminação à LGBT (lésbicas, gays, bissexuais, travestis e transexuais) e também de assegurar através de ações afirmativas e interdisciplinares o combate à intolerância religiosa, ao racismo, à orientação sexual e à discriminação nas escolas de Ensino Médio e profissionalizante”, entre outras estratégias.

Cantagalo, Teresópolis, Carmo, Varre-Sai, Magé, Quissamã, Duas Barras, São João de Meriti e Vassouras objetivam reduzir as desigualdades de gênero desenvolvendo políticas públicas e/ou projetos e ações em parceria com a Secretaria de Assistência

\footnotetext{
${ }^{3} \mathrm{O}$ símbolo + representa as outras pessoas não abrangidas pelas letras iniciais.
} 
Social e Direitos Humanos, além de outras secretarias voltadas para a Educação das relações humanas e a promoção da redução das desigualdades de gênero, classe, raça, etnia, geração, orientação sexual e deficiência, pautando-se pelo princípio da equidade e da igualdade social, a fim de promover um desenvolvimento sustentado e comprometido com a justiça social

Como pode ser visto nos PME apresentados, as questões de gênero e sexualidade não só aparecem muito pouco, como surgem de formas muito distintas de plano para plano, ora em estratégias relativas à formação docente, ora em metas associadas à Educação de Jovens e Adultos (EJA).

Outro ponto a destacar é a pluralidade de formas pela qual essa temática é retratada, sobretudo a forma como é nomeada: gênero; sexualidade; igualdade de gênero; igualdade sexual; intolerância sexual; orientação sexual; bem-estar sexual; e mesmo condição sexual. Esta pluralidade mostra certa ignorância e confusão de boa parte dos textos desses planos em relação às discussões acerca dos conceitos sociológicos de gênero, de sexualidade e de sexo. O resultado desse levantamento só reforça o que já foi dito: é preciso discutir mais, debater mais e promover mais essa temática. Não o fazer é reforçar o obscurantismo e os preconceitos históricos que, promovidos por discursos conservadores e reacionários, pairam sobre a sociedade brasileira e, consequentemente, marcam suas políticas sociais.

\section{Educação Integral em Tempo Integral}

O debate sobre Educação Integral em Tempo Integral é repleto de nuances e não pode resumir-se a um mero aumento da jornada escolar. Educação Integral (CAVALIERE, 2007; COELHO, 2009; MENEZES, 2009; MORGAN, 2015; dentre outros) é aquela que considera o ser humano em sua multidimensionalidade, fornecendo-lhe as ferramentas necessárias para a intervenção social e para a emancipação humana. Tal Educação deve oferecer tempos e espaços educativos diferenciados, nos quais ocorram atividades de matizes multidisciplinares, que sejam capazes de contribuir para o desenvolvimento dos sujeitos, buscando formar homens e mulheres críticos, éticos e justos. Portanto, entendemos que não se trata apenas de um aumento da jornada escolar (escola em Tempo Integral), mas de uma mudança pedagógica e burocrática na própria escola enquanto organização educativa (LIMA, 2011).

Quanto ao Tempo Integral, a partir da meta estabelecida no PNE (BRASIL, 2014), que indica que até o fim do decênio haja $25 \%$ de matrículas em tempo integral, com $50 \%$ das escolas da Educação Básica pública oferecendo-as, buscou-se 
observar os municípios que transcendem à obrigação legal e comprometem-se com uma oferta superior à imposta pela União. Na análise dos PME do Rio de Janeiro, observou-se que apenas sete municípios previram um percentual acima do estabelecido na meta nacional em, pelo menos, um dos dois indicadores escolas com oferta de Tempo Integral e número de matrículas em Tempo Integral (Quadros 1 e 2).

Quadro 1 - Percentual previsto acima do nacional - escolas em tempo integral

\begin{tabular}{|l|c|}
\hline Município & Percentual de escolas \\
\hline Mesquita & $80 \%$ \\
\hline Rio Claro & $100 \%$ \\
\hline São José de Ubá & $58 \%$ \\
\hline Saquarema & $60 \%$ \\
\hline
\end{tabular}

Fonte: Elaborado pelos autores (2017)

Quadro 2 - Percentual previsto acima do nacional - alunos em tempo integral

\begin{tabular}{|l|c|}
\hline Município & Percentual de alunos \\
\hline Angra dos Reis & $50 \%$ \\
\hline Itaboraí & $30 \%$ \\
\hline Rio Claro & $75 \%$ \\
\hline Saquarema & $40 \%$ \\
\hline Trajano de Morais & $40 \%$ \\
\hline
\end{tabular}

Fonte: Elaborado pelos autores (2017)

Como pode ser observado nos Quadros 1 e 2, apenas dois municípios - Rio Claro e Saquarema - previram percentuais de escolas e alunos em tempo integral acima da meta nacional. O município de Mangaratiba, ao afirmar que já alcançou a meta proposta no PNE, propõe o aumento do atendimento em $10 \%$ acima do já existente. A maioria dos percentuais constantes nos Planos Municipais analisados apresentam metas idênticas à do PNE, embora seja muito grande o número de municípios que, analisando sua realidade, optaram por incluir na letra da lei percentual menor do que o previsto na lei nacional. Dos planos analisados, 61 deles previram percentuais de escolas e alunos idênticos ao PNE, o que corresponde a $68 \%$ do total. Daqueles que optaram por seguir metas diferentes, temos o seguinte panorama apresentado no Quadro 3. 
Quadro 3 - Municípios com metas diferentes do Plano Nacional de Educação (PNE)

\begin{tabular}{|l|c|c|}
\hline & Maior que a meta do PNE & Menor que a meta do PNE \\
\hline Escolas & 4 municípios & 12 municípios \\
\hline Alunos & 5 municípios & 7 municípios \\
\hline
\end{tabular}

Fonte: Elaborado pelos autores (2017)

Há ainda os municípios que não citaram nos textos de suas leis um dos dois indicadores. No que tange ao percentual de escolas, omitiram-se Itaguaí e Sapucaia, ao passo que a omissão quanto ao percentual de alunos deu-se nos PME de Araruama, Itaocara, Paraty e Natividade. Itatiaia cita no corpo de seu PME 30\% da rede de ensino, não especificando que etapas estavam contempladas.

Além do cumprimento das metas relativas aos percentuais de escolas com oferta de tempo integral, e de alunos atendidos por ela, a Educação Integral exige também investimentos em infraestrutura, formação e valorização de profissionais de Educação e áreas afins, mudanças no currículo, na avaliação, no planejamento de ações, entre outros. Concordamos que

[...] não há relação direta entre aumento de carga horária diária e melhoria da qualidade educacional, entretanto, no contexto brasileiro, cujo processo histórico e a configuração social são marcadas por grandes desigualdades nas oportunidades, esta ampliação se faz absolutamente necessária. Para a ampliação da visão de mundo destes alunos, a escola precisa proporcionar experiências culturais, esportivas e de lazer buscando uma formação mais completa. Para que tais bens culturais sejam experimentados pelos alunos de maneira responsável e eficiente, o tempo representa elemento fundamental (MORGAN, 2015, p. 84).

A formação em serviço, em especial, a formação dos professores, é apontada como o principal elemento nesse processo de construção do currículo de escolas que proporcionem Educação Integral em Tempo Integral. Branco (2012) afirma que é necessária uma formação continuada diferenciada para a atuação em escolas de Tempo Integral e que essa deve ser oferecida pelos sistemas de ensino. Nesse sentido, ainda segundo a autora, a reorganização da escola deve contribuir "para a busca e a compreensão dos conhecimentos não construídos, e para a reflexão coletiva entre seus pares, sobre os seus saberes e práticas sobre e na ação para a construção da sua autonomia e interação profissional" (BRANCO, 2012, p. 252). 
A afirmação de Branco nos revela a necessidade de tempos-espaços disponíveis para essa reflexão. No entanto, menos da metade dos PME do Estado do Rio de Janeiro previram em suas estratégias a jornada integral de professores. Dos 89 planos municipais de Educação analisados, 39 planos abordaram a ampliação de carga horária dos docentes. Ainda assim, na maior parte deles, não foi possível detectar precisamente qual seria, em números, a quantidade de horas em que o profissional ficaria na instituição escolar.

Outro ponto chamou-nos atenção na análise dos planos: em 44 PME, foram encontrados o termo "formação de recursos humanos" para a Educação em Tempo Integral. Quando falamos em recursos humanos, entendemos, a princípio, que os professores são parte integrante desse universo. Entretanto, não fica claro se nossa percepção é verdadeira, tendo em vista que, em muitos deles, também é citada a formação de professores, e/ou de profissionais da Educação, ou algo semanticamente similar. De todo modo, no que tange ao professor, a ampliação do universo acadêmico coloca esse agente em contato com saberes teóricos e formas de olhar para a prática pedagógica, por ele vivenciada na escola, mas não somente, visto que a cidade coloca-se como interlocutora das novas demandas educacionais (MORGAN, 2015).

\section{Qualidade}

A análise dos conceitos de qualidade nos Planos é algo de suma importância, porém, por vezes, banalizado. Ao estudarmos o PNE, direcionamos, em um primeiro momento, as questões relacionadas à qualidade à Meta sete, cuja redação é: "Fomentar a qualidade da Educação Básica em todas as etapas e modalidades, com melhoria do fluxo escolar e da aprendizagem, de modo a atingir as seguintes médias nacionais no Ideb [Índice de Desenvolvimento da Educação Básica] [...]" (BRASIL, 2014). Porém, trata-se de uma associação por demais simplista, uma vez que todas as 20 metas buscam, em certa medida, a melhoria da qualidade da Educação, afinal, esse é o objetivo central de qualquer Plano de Educação.

A meta sete do PNE estipula objetivamente resultados a serem obtidos por cada segmento no Ideb. A maioria dos municípios fez o mesmo em seus planos; quase a totalidade alocou na meta sete as informações relacionadas ao índice. Alguns trouxeram as metas municipais; outros reproduziram textualmente a meta nacional. O grande problema é que, como há uma multiplicidade de estratégias, muitos municípios permitiram uma relação direta entre qualidade e Ideb, como se bastasse alcançar as metas estipuladas para garantir uma Educação de qualidade para todos. 
Como Najjar e Mocarzel (2013) trazem, a própria descrição da função do Ideb, apresentada pelo Ministério da Educação na data de sua criação, 2007, já afirmava que se tratava de um indicador para medir a qualidade, tanto das escolas, como dos sistemas de ensino. Sendo assim, é natural que o resultado do Ideb torne-se sinônimo de qualidade educacional em outros documentos, seguindo a versão oficial. Porém, diversos autores contestam essa relação direta entre indicador e qualidade (ALMEIDA; DALBEN; FREITAS, 2013; ESTEBAN; FETZNER, 2015). Por ser um indicador quantitativo de grande abrangência, o Ideb apresenta-nos algumas informações importantes, mas possui inúmeras limitações que impedem que o mesmo dê conta da riqueza de fatores que formam a ideia de qualidade.

Os PME de mais de 70 municípios tratam como sinônimos Qualidade e Resultado. Podemos citar alguns planos em que isso é muito claro, como Barra Mansa, Casemiro de Abreu, Quatis, Italva e São Francisco do Itabapoana. Outros documentos, inclusive, fazem defesas acaloradas do Índice, como é o caso de Teresópolis e de Comendador Levy Gasparian. O PME de Paracambi chega ao cúmulo de utilizar a expressão "Padrão MEC de qualidade".

Tantos outros planos propõem que, além do Ideb, a Educação municipal seja monitorada por um indicador próprio, a ser criado nos anos seguintes à aprovação, como por exemplo, Valença, Rio Claro, São Fidélis, Mesquita, Sumidouro, Rio Bonito, Carapebus e Iguaba Grande, que chega a nomear seu próprio índice, o "Índice de Qualidade - IQ" e Tanguá, com a implementação, no primeiro ano de vigência do PME, da prova "Avalia Tanguá".

Alguns municípios já contam com avaliações próprias, com nomes bem significativos, como é o caso de Itaboraí (Provita), Rio das Ostras (Saero) e, novamente, Teresópolis (Avance). Vassouras foca seus esforços também nos resultados do Sistema de Avaliação da Educação do Estado do Rio de Janeiro (Saerj) e Saerjinho, avaliações estaduais. O caso mais significativo é Duas Barras, que apresenta uma proposta de "sondagem" na Educação Infantil, contrariando os princípios da LDB (BRASIL, 1996). O eufemismo utilizado acaba por camuflar o real sentido da proposta.

As avaliações externas são instrumentos complexos, que precisam ser repensados. De acordo com Sacristán e Pérez Gomez (2007, p. 32): “O controle de fora, apesar do que anuncia, não cumpre com o objetivo de igualar as oportunidades entre as escolas de diferente qualidade." Ou seja, se a avalição externa fosse a solução para a melhoria da qualidade, o Brasil já teria uma 
Educação perfeita, dado o grande número de exames de larga escala a que nossos alunos são submetidos.

Há, nos meios acadêmicos e no senso comum, uma falsa relação entre testes e qualidade, como se a quantidade de provas aumentasse a qualidade da Educação praticada. Alguns países que investiram em testagem intensamente, como é o caso dos Estados Unidos, estão agora revendo seus programas e tirando a ênfase que era dada à avaliação após sucessivas decepções em termos de resultados (RAVITCH, 2010).

Apenas como exemplos positivos - ainda que sem questionar a validade do Ideb - citamos três municípios: Angra dos Reis, Cabo Frio e Magé. No documento do primeiro, a meta da qualidade é a única a mencionar a necessidade de respeitar-se o Projeto Político Pedagógico (PPP) das escolas, ressaltando sua autonomia, a dos professores e as metas próprias de cada unidade. Se entendemos, assim como Gadotti (2002, p. 36), que o PPP se apoia no "envolvimento das pessoas: comunidade interna e externa à escola" e "na participação e na cooperação das várias esferas de governo", os PME precisam respeitar a autonomia das escolas, para que possuam organicidade com o que está em prática.

O debate nacional em torno do currículo, mais precisamente sobre a Base Nacional Comum Curricular, está na agenda do dia. De acordo com Oliveira (2009), tentativas de reformas curriculares acontecidas ao longo do tempo, no Brasil, resultaram em fracassos históricos. Ainda segundo o autor, somente dos anos 1930 aos anos 2000, foram cinco tentativas frustradas de implementação de currículos nacionais, por mais que cada uma tenha tido seu formato e suas próprias filiações teóricas.

Mesmo com todo o debate nacional, muitos municípios, cujos planos foram analisados, não se privaram, em estratégias ligadas à melhoria da qualidade, de propor reformas curriculares no âmbito municipal. O caso citado anteriormente é muito significativo, por demonstrar como as avaliações de larga escala pautam o que se deve ensinar, e como muitas escolas e redes aderem a uma perspectiva de treinamento para testes. Porém, o caso de Tanguá é ainda mais expressivo: a meta sete conta com poucas estratégias, sendo que, quase todas, estão voltadas para a concepção de uma matriz curricular direcionada à Prova Brasil, o que contamina inclusive a formação de professores, com uma estratégia de focar os processos formativos nesse mesmo instrumento avaliativo nacional, limitando o pensamento e a criticidade dos docentes. 
Outros planos como os de Areal, Iguaba Grande, Quissamã, Rio Bonito e Teresópolis propõem mudanças curriculares em prol da qualidade. Macaé propõe essa mudança com a oferta de disciplinas eletivas aos alunos. Mangaratiba e Angra dos Reis propõem a criação de colegiados e fóruns para o debate curricular no município. Outra preocupação de alguns municípios é o Programa Internacional de Avaliação de Estudantes (Pisa).

Por se tratar de uma estratégia do PNE, o exame passou a compor o rol de prioridades dos municípios, entre eles, Cantagalo, Mangaratiba, Bom Jardim e São Francisco de Itabapoana. Alguns citam, inclusive, a necessidade de avaliar, nos instrumentos municipais, a disciplina de Ciências, para contemplar os conteúdos solicitados pelo programa internacional.

A visão empresarial da Educação Pública também integra a lista de estratégias. O mesmo PME de Itaguaí, que defende a ideia de qualidade para a inclusão social, propõe a existência de parcerias público-privadas para reformular as escolas. Não se trata de um caso tão recorrente, mas, tampouco, é isolado. Em outros setores, como a saúde, por exemplo, esse tipo de modelo de administração é cada vez mais comum. Na cidade do Rio de Janeiro, hospitais e clínicas já são administrados por Organizações Sociais (OS).

A ideia de responsabilidade é um tanto quanto dúbia em se tratando de Educação. Não se deve confundir a responsabilidade, sinônimo de cuidado e comprometimento, aquilo que se deve ter enquanto professor ou gestor, com a noção de responsabilização, também conhecida como accountability.

Accountability indica frequentemente uma forma hierárquicoburocrática ou tecnocrática e gerencialista de prestação de contas que, pelo menos implicitamente, contém e dá ênfase a consequências ou imputações negativas e estigmatizantes, as quais, não raras vezes, consubstanciam formas autoritárias de responsabilização das instituições, organizações e indivíduos (AFONSO, 2012, p. 472).

Em diversos planos há metas que pregam a responsabilização dos professores e alunos, numa perspectiva que Ball $(2005,2010)$ apresenta como performatividade, ligada ao controle e exercício de poder e a formas de organização do espaço público, de acordo com a lógica do mercado.

Finalmente, vale destacar que há muitos textos de Planos Municipais pesquisados que apresentam questões graves em relação à própria significação de plano. 
Desde que os primeiros Planos de Educação foram pensados, a plurianualidade compunha sua formatação, justamente para que fosse visto como um instrumento do estado, não do governo federal. Porém, muitos dos PME do Estado do Rio de Janeiro assumiram um caráter personalista, defendendo bandeiras da gestão que conduziu sua formulação.

Os casos mais emblemáticos referem-se a três municípios. O plano de Miracema traz, em seu corpo, o nome do autor de cada meta ao lado. Ou seja, o documento, que deveria ser da territorialidade, do município, passa a ter "donos", autores, responsáveis pelo sucesso (ou pelo fracasso) das mesmas. Os municípios de Trajano de Moraes e de Seropédica falam diretamente da atual gestão, enaltecendo os feitos da prefeitura e tomando para si as glórias de terem produzido os respectivos PME.

\section{Considerações finais}

Nesse texto, focou-se naquilo que Ball e Bowe (1992) entendem por contexto da produção de textos. Fazendo uso da Análise de Conteúdo, foram analisadas diferentes filiações do conteúdo, antecipando projeções sobre o que aqueles textos poderiam (e podem) vir a ser no contexto da prática. Considerando a natureza complexa e controversa das políticas educacionais, a abordagem do ciclo de políticas destaca os processos micropolíticos e a ação dos atores que lidam com a política no nível local, enfatizando a importância da articulação entre os processos micro e macro nas análises das políticas educacionais.

Entendemos que a elaboração de um plano educacional não é tarefa fácil; exige compromisso político e técnico, sistematização de informações, muitas vezes dispersas, e adequação constante entre o desejado e o possível. A busca por uma Educação de qualidade, em que todos frequentem uma escola autônoma, bem estruturada, com professores bem formados e valorizados deve ser constante, por maiores que os obstáculos possam parecer. Vale lembrar que entendemos Educação de qualidade como aquela que, do ponto de vista social, contribui para a equidade e, do ponto de vista econômico, refere-se à eficiência do uso de recursos (DOURADO; OLIVEIRA; SANTOS, 2007).

Nesse sentido, os planos de Educação ajudam-nos a traçar metas e estratégias reais, compelem-nos a deixarmos a esfera do desejo e a partirmos para as ações práticas. A conjuntura federal de quando foi aprovado levou à existência de um plano nacional arrojado, embora muitas das metas propostas no PNE, em função das mudanças políticas ocorridas recentemente no Brasil, hoje já se mostrem letra morta. Mas no âmbito federal parece haver menos cobrança pelo cumprimento 
da lei, vide a ação mais efetiva do Ministério Público junto aos municípios para que realizem o que apresentaram em seus planos.

A efetividade do PME depende em grande parte do real dimensionamento das demandas educacionais, das fragilidades, dos desafios e das potencialidades locais e dos modelos de gestão que se efetivam. No caso do PME, essas demandas e necessidades precisam ser comparadas com a capacidade atual e futura de investimentos municipais e possíveis aportes do governo estadual, da União e de outras fontes. O PME deve articular-se aos demais instrumentos de planejamento. Os insumos necessários para a execução dos planos de Educação terão de constar nos orçamentos da União e dos estados para que apoiem técnica e financeiramente os municípios ao longo da década. Na Prefeitura, instrumentos de planejamento terão de se vincular ao plano decenal de Educação: Plano Plurianual (PPA), Lei de Diretrizes Orçamentárias (LDO), Lei Orçamentária Anual (LOA), Plano de Ações Articuladas (PAR), entre outros, para que seja efetivada uma rede colaborativa entre os entes federados e a sociedade e os planos possam sair do campo das ideias e se tornarem políticas na prática. 


\section{The Municipal Plans of Education of the State of Rio de Janeiro: a mapping of goals, strategies and challenges}

\section{Abstract}

This article stems from a research carried out with the Municipal Plans of Education of 89 municipalities of the State of Rio de Janeiro. The analytical categories of gender, full-time education and quality were selected based on the policy cycle and content analysis of legal texts, seeking to understand how they were portrayed in the plans and ideological affiliations. When analyzing the context of the production of texts and their unfolding, a critical perspective was sought on the function of the planning of educational policies.

Keywords: Municipal Plan of Education. Policy Cycle. Rio de Janeiro.

\section{Los Planes Municipales de Educación del Estado de Río de Janeiro: un mapeo de objetivos, estrategias y desafíos}

\section{Resumen}

Este artículo es el resultado de una investigación realizada con los Planes Municipales de Educación de 89 municipios del Estado de Río de Janeiro. Desde el enfoque del ciclo de políticas y del análisis de contenido de los textos legales, se seleccionaron las categorías analíticas Género, Educación a Tiempo Completo y Calidad, buscando comprender cómo fueron representadas en los planes y qué afiliaciones ideológicas las respaldaron. Al analizar el contexto de la producción de texto y su desarrollo, se buscó una perspectiva critica sobre el papel de la planificación de políticas educativas.

Palabras clave: Plan Municipal de Educación. Ciclo de Políticas. Río de Janeiro. 


\section{Referências}

AFONSO, A. J. Para uma conceitualização alternativa de accountability em educação. Educação \& Sociedade, Campinas, v. 33, n. 119, p. 471-484, abr.-jun. 2012. https://doi.org/10.1590/S0101-73302012000200008

ALMEIDA, L.; DALBEN, A.; FREITAS, L. C. O Ideb: limites e ilusões de uma política pública educacional. Educação \& Sociedade, Campinas, v. 34, n. 125, p. 1153-1174, out.-dez. 2013. https://doi.org/10.1590/S0101-73302013000400008

BALL, S. J. Profissionalismo, gerencialismo e performatividade. Cadernos de Pesquisa, São Paulo, v. 35, n. 126, p. 539-564, set.-dez. 2005. https://doi.org/10.1590/S0100-15742005000300002

BALL, S. J. Performatividades e fabricações na economia educacional: rumo a uma sociedade performativa. Educação \& Realidade, Porto Alegre, v. 35, n. 2, p. 37-55, maio-ago. 2010. Disponível em: $<$ https://seer.ufrgs.br $</$ educacaoerealidade/article/view/15865/9445>. Acesso em: 11 nov. 2017.

BALL, S. J.; BOWE, R. Subject departments and the "implementation" of National Curriculum policy: an overview of the issues. Journal of Curriculum Studies, Londres, v. 24, n. 2, p. 97-115, Mar. 1992. https://doi.org/10.1080/0022027920240201

BALL, S. J.; MAGUIRE, M.; BRAUN, A. Como as escolas fazem as políticas: atuação em escolas secundárias. Ponta Grossa: Editora UEPG, 2016.

BARDIN, L. Análise de conteúdo. Lisboa: Edições 70, 1994.

BAYARDO, B. Sex and the curriculum in Mexico and the United States: a heavy burden in ignorance. In: STROMQUIST, N. P. (ed.). Gender dimensions in education in Latin America. Washington, DC: OEA, 1995. p. 157-186.

BORDIGNON, G. Caminhar da educação brasileira: muitos planos, pouco planejamento. In: SOUZA, D. B.; MARTINS, A. M. Planos de educação no Brasil: planejamento, políticas, práticas. São Paulo: Loyola, 2014. p. 29-53.

BRANCO, V. A política de formação continuada de professores para a educação integral. In: MOLL, J. et al. Caminhos da educação integral no Brasil: direito a outros tempos e espaços educativos. Porto Alegre: Penso, 2012. p. 246-257. 
BRASIL. Documento norteador para elaboração de Plano Municipal de Educação - PME. Brasília, DF: Secretaria de Educação Básica, 2005.

BRASIL. Lei $\mathrm{n}^{\circ}$ 4.024, de 20 de dezembro de 1961. Fixa as diretrizes e bases da Educação Nacional. Diário Oficial da União, Brasília, DF, dez. 1961.

BRASIL. Lei ${ }^{\circ}$ 9.394, de 20 de dezembro de 1996. Estabelece as diretrizes e bases da Educação Nacional. Diário Oficial da União, Brasília, DF, 20 dez. 1996.

BRASIL. Lei $\mathrm{n}^{\circ} 10.172$, de 9 de janeiro de 2001. Aprova o Plano Nacional de Educação e dá outras providências. Diário Oficial da União, Brasília, DF, 10 jan. 2001.

BRASIL. Lei $\mathrm{n}^{\circ} 13.005$, de 25 de junho de 2014. Aprova o Plano Nacional de Educação e dá outras providências. Diário Oficial da União, Brasília, DF, 26 jun. 2014.

CAVALIERE, A. M. Tempo de escola e qualidade na educação pública. Educação \& Sociedade, Campinas, v. 28, n. 100, p. 1015-1035, out. 2007. htps://doi.org/10.1590/S0101-73302007000300018

COELHO, L. M. (org.). Educação integral em tempo integral: estudos e experiências em processo. Petrópolis: DP et Alii, 2009.

DOURADO, L. F.; GROSSI JUNIOR, G.; FURTADO, R. A. Monitoramento e avaliação dos planos de educação: breves contribuições. Revista Brasileira de Política e Administração da Educação, Goiânia, v. 32, n. 2, p. 449-461, maio/ago. 2016. https://doi.org/10.21573/vol32n22016.67198

DOURADO, L. F.; OLIVEIRA, J. F.; SANTOS, C. A qualidade da educação: conceitos e definições. Brasília, DF: Inep, 2007.

ESTEBAN, M. T.; FETZNER, A. R. A redução da escola: a avaliação externa e o aprisionamento curricular. Educar em Revista, Curitiba, n. spe 1, p. 75-92, 2015. https://doi.org/10.1590/0104-4060.41452

GADOTTI, M. Perspectivas atuais de educação. Porto Alegre: Artes Médicas, 2002.

LIMA, L. A escola como organização educativa. São Paulo: Cortez, 2011. 
MENDES, D. T. O planejamento educacional no Brasil. Rio de Janeiro: Eduerj, 2000.

MENEZES, J. Educação integral e tempo integral na educação básica: da LDB ao PDE. In: COELHO, L. M. C. C. (Org.). Educação integral em tempo integral: estudos e experiências em processo. Petrópolis, RJ: DP et Alli, 2009. p. 21-37.

MORGAN, K. V. O Programa Mais Educação no Formigueiro das Américas: a política de indução à Educação Integral no município de São João de Meriti. 2015. Dissertação (Mestrado em Educação) - Niterói: Universidade Federal Fluminense, 2015.

NAJJAR, J.; MOCARZEL, M. Políticas públicas para a qualidade: notas sobre a realidade brasileira. In: NAJJAR, J.; CASTAÑO, L.; DIAZ, F. (orgs.). Desafios e perspectivas na educação para Brasil e Colômbia. Niterói: Intertexto, 2013. p. 77-88.

OLIVEIRA, J. F. Educação escolar e currículo: por que reformas curriculares têm fracassado no Brasil? In: DOURADO, L. F. (org.). Políticas e gestão da educação no Brasil: novos marcos regulatórios? São Paulo: Xamã, 2009. p. 49-58.

PEREIRA, S. M. O Sistema Municipal de Ensino em análise: avanços e desafios. Ensaio: Avaliação e Políticas Públicas em Educação, Rio de Janeiro, v. 26, n. 101, p. 1372-1392, out.-dez. 2018. https://doi.org/10.1590/s0104-40362018002601066

RAVITCH, D. The death and life of the great american school system: how testing and choice are undermining education. New York: Basic, 2010.

SACRISTÁN, J. G.; PÉREZ GOMEZ, A. I. Compreender e transformar o ensino. Porto Alegre: Artmed, 2007.

SANTOS, M. Educação do Campo no Plano Nacional de Educação: tensões entre a garantia e a negação do direito à educação. Ensaio: Avaliação e Políticas Públicas em Educação, Rio de Janeiro, v. 26, n. 98, p. 185-212, jan.-mar. 2018. https://doi.org/10.1590/s0104-40362018002600965

SOUZA, D. B.; MARTINS, A. M. (orgs.). Planos de educação no Brasil: planejamentos, políticas, práticas. São Paulo: Loyola, 2014. 
TEIXEIRA, L. Planos de educação no contexto brasileiro e a relação com os sistemas de ensino. In: NAJJAR, J. (org.). Políticas públicas em educação (e outras nem tanto): cidadania, trabalho docente e identidade. Niterói: Intertexto, 2012. p. 21-40.

\section{Informações dos autores}

Jorge Najjar: Doutor em Educação pela Universidade de São Paulo. Professor da Faculdade de Educação e do Programa de Pós-Graduação em Educação da Universidade Federal Fluminense. Contato: jorgenajjar@gmail.com

(iD) https://orcid.org/0000-0002-0491-9298

Marcelo Mocarzel: Doutor em Comunicação pela Pontifícia Universidade Católica do Rio de Janeiro, com Pós-Doutorado em Educação pela Universidade Federal Fluminense. Professor do Programa de Pós-Graduação em Educação da Universidade Católica de Petrópolis e do Centro Universitário La Salle do Rio de Janeiro. Contato: marcelomocarzel@gmail.com

(iD) https://orcid.org/0000-0002-2780-0054

Karine Morgan: Doutoranda e mestre em Educação pela Universidade Federal Fluminense. Professora das Faculdades Integradas Maria Thereza e professora substituta da Faculdade de Educação da Universidade Federal Fluminense. Contato: morgan.uff@gmail.com

(iD) https://orcid.org/0000-0001-5014-5679 